\title{
Outcome of coronary endarterectomy with off-pump coronary artery bypass grafting: A retrospective study
}

\section{Redoy Ranjan and Asit Baran Adhikary}

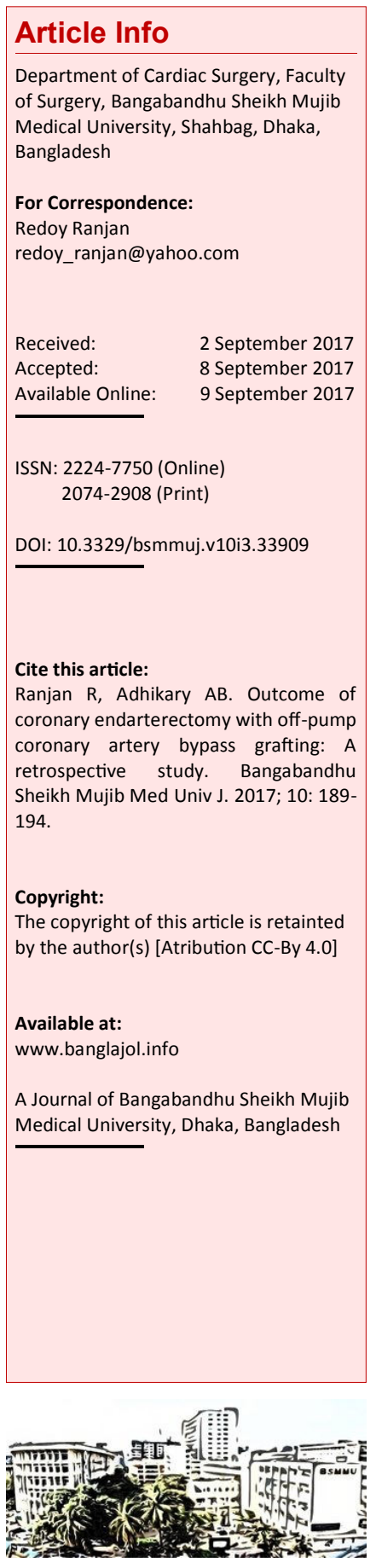

\section{Abstract}

In this study, we assessed the outcome of surgical revascularization technique, coronary artery bypass grafting (CABG) with or without coronary endarterectomy for patients with diffuse coronary artery disease in a single surgeon's practice on 2,189 patients from January 2009 and December 2016. The variables like intubation time, ICU stay, postoperative myocardial infarction, arrhythmia, renal impairment, stroke and ICU mortality were compared. Among these patients, 1,000 patients required coronary endarterectomy in addition to off-pump coronary artery bypass grafting (OPCABG). Initially, the mortality and incidence of postoperative blood transfusion were higher in the group of patients who had coronary endarterectomy in addition to CABG. However, postoperative combined use of heparin, warfarin and double anti-platelet agent was associated with decreased mortality significantly in our study. In comparison to other group, the patients in the combined coronary endarterectomy with CABG group had a higher incidence of male sex, past myocardial infarction and poor left ventricular function. Total myocardial revascularization is attainable when coronary endarterectomy is performed in addition to off-pump coronary artery bypass graft surgery in diffuse coronary artery disease.

\section{Introduction}

In the late 1950s, coronary endarterectomy was described as a surgical technique for the myocardial revascularization. 1 Endarterectomy is the removal of the atheromatous plaque through a plane between the external media and adventitia layers, along these lines restoring the lumen to the supply distal part of artery. In patients with diffuse coronary artery disease, coronary endarterectomy is frequently performing to attain complete myocardial revascularization. In a patient with diffuse coronary artery disease, only coronary artery bypass graft (CABG) does not provide a satisfactory myocardial revascularization, bringing it about incomplete CABG. 1 However, inadequate revascularization does not influence the quick death rate, but rather increase the incidence of reoperations with significant obstruction in vessels, which influences the long-term cardiac function. The patient has repeated attach of angina, more frequent work absence rate, poor performance in stress tests and also need an early coronary reintervention, but complete CABG group of patient has better survival rate. $\underline{2,3}$

Ischemic heart disease patient, who is referred for CABG surgery is getting more complex with multiple comorbidities, like hypertension, diabetes, renal impairment and peripheral artery disease, also a big portion of this group of patients have experienced previous coronary intervention angioplasty. Subsequently, complete myocardial revascularization with only CABG is getting difficult in the presence of complex coronary artery disease. However, coronary endarterectomy is the best alternative way to achieve better revascularization and post-operative results in coronary artery disease. $\underline{4}$

This study evaluates the consequences of coronary endarterectomy in a single surgeon's practice at our institute and to provide details regarding our treatment strategies for patients experiencing diffuse coronary artery disease.

\section{Materials and Methods}

Patients $(n=2,189)$ were evaluated to CABG with or without coronary endarterectomy in a single surgeon's practice from January 2009 to December 2016 (Figure 1). We reviewed the outcome of study population by survival rate, post-operative cardiovascular and neurological event, re-intervention, hemodynamic instability, NYHA class and Canadian class for angina were researched. However, there was a measurable distinction in regard to the 


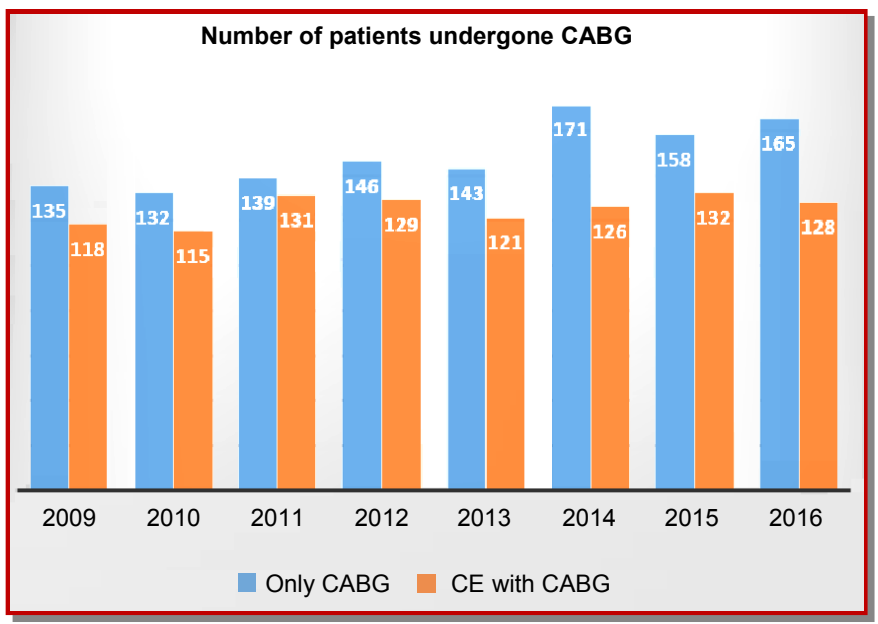

Figure 1: Bar-diagram showing number of patients undergone CABG surgery at different years atheroma. Usually, proximal traction of atheroma was avoided due to chance of competitive flow loss between endarterectomize artery and graft, but more concentration was provided to remove the distal part of the atheroma. Following extraction of plaque from native artery, atheroma specimen was properly inspected and a smooth distal tapper end indicated complete removal of plaque. In addition to this, presence of back flow of blood from the distal part of endarterectomize artery indicated proper removal of the plaque and this is a special characteristic for standard OPCABG coronary endarterectomy. Every cases were performed with single arteriotomy incision and longest atheroma was $14 \mathrm{~cm}$ in size removed from the right coronary artery. 2

Each patient was closely observed postoperatively in ICU with ECG, arterial blood gas analysis, full blood count, S. creatinine, liver function text and chest X-ray. The CK-MB was performed where indicated. Every patient got heparin in early postoperative period for next 48 hours (usually 2-3 hours following surgery); bridging to warfarin from the first post-operative day for 3-6 months. We also used oral combination of clopidogrel with aspirin $(75 \mathrm{mg})$ to anticipate acute thrombosis at the graft and in the native endarterectomies artery. Usually warfarin started with $10 \mathrm{mg}$ daily for first three post -operative days followed by $2.5-5 \mathrm{mg}$ till next 3-6 months post-operatively and dose was adjusted according to INR (targeted INR 1.5-2.5). However, post-operative CT angiogram was performed to demonstrate the graft patency rate in our study during follow-up period. internal mammary artery. Almost all the operations were performed off pump CABG and a few cases required the assistance of cardiopulmonary by-pass, using a membrane oxygenator, utilizing the surgical procedures to acquire the graft. We utilized mechanical stabilizers, the compre-ssion type and suction type to immo-bilize the target coronary artery during grafting. Decision for coronary endarterectomy was done according to peroperative findings, when the targeted coronary artery was totally occluded with long segment stenosis, multi-segmental lesion, or in presence of severely calcified plaques invol-ving distal part of vessel.

In our study, closed technique for coronary endarterectomy was utilized and coronary endarterectomy was performed with the help of delicate ring forceps by slow, sustain, and continuous traction of atheromatous plaque, and trailed by reproduction with anastomosis with preplanned graft. Arteriotomy incision was approximately $8-10 \mathrm{~mm}$ long, however that was extended out for another $5 \mathrm{~mm}$ in few cases, if complete removal of the plaque was not feasible. Exceptionally sensitive ring forceps were utilized to build-up a plane between the media lamina and the

\section{Results}

Among the total 2,189 patients, 1,189 patients underwent only CABG (Group 1) and 1,000 patients underwent CABG with endarterectomy (Group 2) procedure. Twelve hundred endarterectomies were performed in Group 2. $16.5 \%$ of the patients required multiple endarterectomies (1.2 endarterectomies per patient). Of the 1200 endarterectomies, $75.1 \%$ in LCA territory, and only $24.9 \%$ was done in RCA territory. Mean number of graft were $3.0 \pm 0.2$ in without endarterectomy group and $3.3 \pm 0.3$ in coronary endarterectomy group. The mean followup period was $8.5 \pm 3.5$ months (between of 6 to 24 months). The quantities of graft and endarterectomies are appeared in Table I. There were 18\% conversions to on-pump CABG using cardiopulmonary bypass in coronary endarterectomy with CABG Group but only $2.8 \%$ conversions to onpump CABG in only CABG Group. Post-operative ICU mortality rate was $1.7 \%$ without endarterectomy group and $1.8 \%$ in with endarterectomy group. There were no intra-operative mortalities in this study. 
Table I

Characteristics of study population

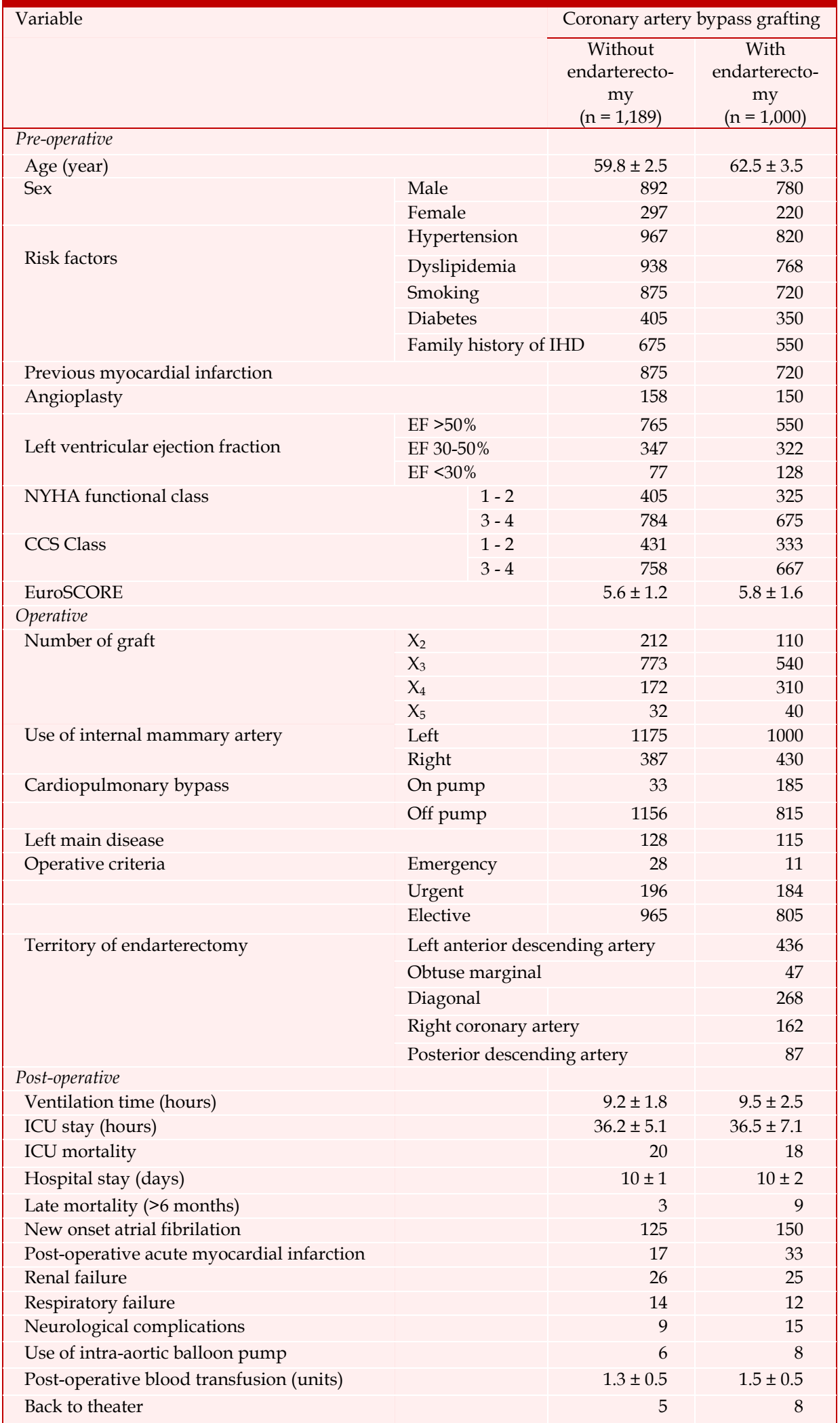

A mean of $1.5 \pm 0.5$ units of blood was transfused post-operatively in CABG with endarterectomy group, which is more than without endarterectomy group, where $1.2 \pm 0.5$ units of blood was trans-fused. About $91 \%$ patients were in regular follow-up in Group 1, whereas $92.7 \%$ patients were in regular follow-up in Group 2. At median follow-up of 2.5 years, 91.8 and $88.5 \%$ of patients were angina free in CABG without endarterectomy group and with endarterectomy group respectively. The rest of the post-operative characteristics including mortality and morbidity are listed in Table I. Only $1.2 \%$ patient of coronary endarterectomy with CABG group presented with chest pain and was hospitalized. But there was no ECG changes in favor of acute MI, however a coronary angiogram was done which demonstrate lesion in a small obtuse marginal artery. The major post-operative morbidity and mortality were compared between two group. There was no significant difference in term of post-operative outcome like MI, renal failure, respiratory failure, neurological complication and use of postoperative IABP.

\section{Discussion}

This study evaluated outcomes of CABG with or without coronary endarterectomy and shown that the complete revascularization of diffuse coronary artery disease enhanced the early and late post-operative outcomes following CABG. The mean age of study population was $59.8 \pm 2.5$ and $62.5 \pm 3.5$ in only CABG group and coronary endarterectomy with CABG group respectively. In this review, $16.5 \%$ of the patients required multiple endarterectomies in coronary endarterectomy with CABG group i.e. 1.2 endarterectomies per patient. Out of total endarterectomies, $75.1 \%$ in LCA territory, and only $24.9 \%$ was done in RCA territory. The mean graft number were $3.0 \pm 0.2$ and $3.3 \pm 0.3$ in only CABG group and coronary endarterectomy with CABG group respectively. There were $18 \%$ conversions to on-pump CABG using 
cardiopulmonary bypass in coronary endarterectomy with CABG Group. Post-operative ICU mortality rate was $1.7 \%$ in Group 1, and 1.8\% in Group 2. There were no intra-operative mortalities in this study. The mean follow-up period was $8.5 \pm 3.5$ months (between of 6 to 24 months). In our study, a mean of more blood was transfused postoperatively in coronary endarterectomy with CABG group rather than only $\mathrm{CABG}$ group. At median follow-up of 2.5 years, 91.8 and $88.5 \%$ of patients were angina free in only CABG group and coronary endarterectomy with $\mathrm{CABG}$ group respectively.

Coronary endarterectomy with off-pump CABG surgery provide better postoperative outcome, reduce the incidence of postoperative morbidity and mortality and also the duration of hospital stay. .6 In a study, Smith et al. observed that majority of patients are belongs to 61 to 70 years age group, which is similar to our study.7 Islamoglu et al. shows that total myocardial revascularization improves LV function postoperatively. $\underline{8}$ Complete revascularization especially left coronary (LCA) territory has been identified as a most critical values that influences post-operative patient's recovery. $.9-11$ Vigorous myocardial contraction in the LAD territory helps in extraction of the distal atheroma by close traction technique coronary endarterectomy more easily as compared to the RCA region. $.2,12,13$ This study also showed that it is easier to remove atheroma from LAD than RCA, which is also described in other article. Though coronary endarterectomy procedure is as yet a matter of controversy, but the low incidence of readmission to the intensive care unit (ICU), chest re-open for bleeding, infection, transient ischemic attack, and stroke in this CABG with endarterectomy group contrasts positively with published OPCABG articles..$\underline{9,14,15}$

Following coronary endarterectomy, anticoagulation therapy with heparin infusion used in order to prevent graft thrombosis, bridging to oral warfarin for next 3-6 months provide best post-operative outcome, which is also similar to this study results. $\underline{11,16,17}$ In a study, Djalilian et al. shows only $9 \%$ of their patients got angina at $46 \pm 19$ months followup, though Gill et al. observed that $15 \%$ patients having angina at a mean follow-up of $36 \pm 16$ months.12, 16 In this study, only $0.8 \%$ and $1.5 \%$ patients had transient ischemic attack with full recovery in CABG without endarterectomy group and with endarterectomy respectively, which also supported by another study. 18 However, Vohra et al. observed only $10 \%$ recurrence of angina following OPCABG with coronary endarterectomy which is similar to our study. $\underline{19}$ But, in a study Christakis et al. observed $35 \%$ recurrence rate of angina at 5 years follow-up in their study, which is significantly higher than our study. $\underline{20}$ However, multiple published literature shows that acute MI is a noteworthy complication following coronary endarterectomy caused by acute graft thrombosis and the incidence rate is 1.5 to $19 \% . \underline{13,21-23}$

In this study, the mortality rate in both study group was associated with aging process, specially age more than 70 years, emergency or urgent CABG surgery, pre-operative renal function impairment, multiple comorbidities like diabetes mellitus, peripheral vascular disease, and LV dysfunction, which is supported by other authors. $\underline{14,19,24}$ In a study following coronary endarterectomy with OPCABG, Erylimaz et al. shows no mortality at 1year follow-up21 but Naseri et al. who compared coronary endarterectomy with both on pump and off pump CABG, described $2.2 \%$ mortality rate in a study involving 44 patients. $\underline{18}$ Though Vohra et al. observed 1-year survival rate is $91.5 \%$, and 5-year survival rate is $87.9 \%$ are amazing as compared to others study result.19 Many authors describe the incidence of early mortality after coronary endarterectomy with OPCABG is $2-15 \% .20,22$ But interestingly with regards to coronary endarterectomy with OPCABG, Careaga et al. revealed a 30-day mortality of $0 \%$ in their small series study. 25 Despite the advancement of medical science, the morbidity and mortality following coronary endarterectomy with $\mathrm{CABG}$ is more prominent than with CABG alone. $11,13,15,25$ However, Atik et al. observed in a study that female sex, previous MI, left main disease, diabetes mellitus, and a low ejection fraction $(<35 \%)$ to be related with higher incidence of early mortality which also supported by other published articles. $23,26,27$ But, the consequences of the present review are not concordance with these discoveries as in the both study group patients had a lower mortality in our review probably due to prompt anticoagulation therapy in early postoperative days.

This study shows that only CABG surgery is sufficient to provide total myocardial revascularization in uncomplicated coronary artery disease. However, in complex coronary artery disease like diffuse lesion, stent restenosis, and LV dysfunction, we need to do concurrent coronary endarterectomy with CABG to achieved good distal run-off and better post-operative outcome. Though in coronary endarterectomy with CABG group comprises higher risk population, but postoperative outcome was similar to only CABG group population. Endarterectomy of the circumflex artery is unnecessary when the vessel is small, in presence of diffuse disease and severe calcification of vessel. However, post-operative anticoagulation therapy and surgical skills remains the key stream in our study and coronary endarterectomy was not found to be independently associated with mortality in the analysis for the predictors of mortality. 


\section{Conclusion}

In diffuse coronary artery disease, coronary endarterectomy with off-pump coronary artery bypass graft surgery provides total myocardial revascularization and better postoperative outcome. However, surgical skill, patient's selection and postoperative anticoagulation therapy are main stream for better outcome despite the higher risk group, severe LV dysfunction, and diffuse coronary lesion.

\section{Conflict of interest}

No potential conflict of interest with the respect of authorship, research or publication of this article.

\section{References}

1. Bailey CP, May A, Lemmon WM. Survival after coronary endarterectomy in man. J Am Med Assoc. 1957; 164: 641-46.

2. Ranjan R, Adhikary D, Saha H, Saha SK, Hasan K, Adhikary AB. Coronary atheroma $[14 \mathrm{~cm}]$ extracted from the right coronary artery during off-pump coronary artery bypass grafting. Bangabandhu Sheikh Mujib Med Univ J. 2017; 10: 97-100.

3. Jones EL, Craver JM, Guyton RA, Bone DK, Hatcher Jr. CR, Riechwald N. Importance of complete revascularization in performance of the coronary bypass operation. Am J Cardiol. 1983; 51: 7-12.

4. Asimakopoulos G, Taylor KM, Ratnatunga CP. Outcome of coronary endarterectomy: A casecontrol study. Ann Thorac Surg. 1999; 67: 989-93.

5. Tyszka AL, Fucuda LS, Tormena EB, Campos ACL. Obtenção da veia safena magna através de acesso minimamente invasivo para revascularizações miocárdicas. Rev Bras Cir Cardiovasc. 2001; 16: 105 -13 .

6. Groves LK, Loop FD, Silver GM. Endarterectomy as a supplement to coronary artery-saphenous vein bypass surgery. J Thorac Cardiovasc Surg. 1972; 64: 514-22.

7. Smith P, Goodnough L, Levy J, Poston R, Short M, Weerakkody G, Lenarz LA. Mortality benefit with prasugrel in the TRITON-TIMI 38 coronary artery bypass graft cohort: Risk-adjusted retrospective data analysis. J Am Coll Cardiol. 2012; 60: 388-96.

8. Islamoglu F, Apaydin A, Posacioglu H, Ozbaran M, Hamalu A, Buket S, Telli A, Durmaz I. Coronary artery bypass grafting in patients with poor left ventricular function. Japan Heart J. 2002; 43: 343-56.

9. Sabik JF, Gillinov AM, Blackstone EH, Vacha C, Houghtaling PL, Navia J, Smedira NG, McCarthy PM, Cosgrove DM, Lytle BW. Does off-pump coronary surgery reduce morbidity and mortality? J
Thorac Cardiovasc Surg. 2002; 124: 698-707.

10. Marzban M, Karimi A, Ahmadi H, Davoodi S, Abbasi K, Movahedi N, Salehiomran A, Abbasi SH, Kawoosi Y, Yazdanifard P. Early outcomes of double-vessel coronary endarterectomy in comparison with single-vessel coronary endarterectomy. Tex Heart Inst J. 2008; 35: 119-24.

11. Hasan MS, Adhikary AB, Rahman M. Clinical outcome in patients undergoing coronary artery bypass grafting using radial artery. Bangladesh Med Res Counc Bull. 2007; 33: 107-08.

12. Djalilian AR, Shumway SJ. Adjunctive coronary endarterectomy: Improved safety in modern cardiac surgery. Ann Thorac Surg. 1995; 60: 1749-54.

13. Puskas JD, Thourani VH, Kilgo P, Cooper W, Vassiliades T, Vega JD, Morris C, Chen E, Schmotzer BJ, Guyton RA, Lattouf OM. Off-pump coronary artery bypass disproportionately benefits high-risk patients. Ann Thorac Surg. 2009; 88: 1142-47.

14. Takanashi S, Fukui T, Miyamoto Y. Coronary endarterectomy in the left anterior descending artery. J Cardiol. 2008; 52: 261-68.

15. Adhikary AB, Ahsan K, Husain SS, Saha SK, Sohan $\mathrm{AM}$, Hasan MN. Coronary artery bypass graft in a patient with markedly reduced ejection fraction. Chattagram Maa-O-Shishu Hospital Med Coll J. 2014; 13: 77-79.

16. Gill IS, Beanlands DS, Boyd WD, Finlay S, Keon WJ. Left anterior descending endarterectomy and internal thoracic artery bypass for diffuse coronary disease. Ann Thorac Surg. 1998; 65: 659-62.

17. Elbardissi AW, Balaguer JM, Byrne JG, Aranki SA. Surgical therapy for complex coronary artery disease. Semin Thorac Cardiovasc Surg. 2009; 21: 199-206.

18. Naseri E, Sevinc M, Erk MK. Comparison of offpump and conventional coronary endarterectomy. Heart Surg Forum. 2003; 6: 216-19.

19. Vohra HA, Kanwar R, Khan T, Dimitri WR. Early and late outcome after off-pump coronary artery bypass graft surgery with coronary endarterectomy: A single-center 10-year experience. Ann Thorac Surg. 2006; 81: 1691-96.

20. Christakis GT, Rao V, Fremes SE, Chen E, Naylor D, Goldman BS. Does coronary endarterectomy adversely affect the result of bypass surgery? J Card Surg. 1993; 8: 72-78.

21. Eryilmaz S, Inan MB, Eren NT, Yazicioglu L, Corapcioglu T, Akalin H. Coronary endarterectomy with off-pump coronary artery bypass surgery. Ann Thorac Surg. 2003; 75: 865-69.

22. Fukui T, Tabata M, Taguri M, Manabe S, Morita S, Takanashi S. Extensive reconstruction of the left anterior descending coronary artery with an internal thoracic artery graft. Ann Thorac Surg. 2011; 91: 445-51. 
23. Mandal S, Ghosh SK, Rahman M, Majumder A, Ranjan R, Adhikary D, Hasan K, Islam MZ, Adhikary AB. Health related quality of life among the coronary heart disease patients. Cardiovasc J. 2016; 9: 43-48.

24. LaPar DJ, Anvari F, Irvine JN, Kern JA, Swenson BR, Kron IL, Ailawadi G. The impact of coronary artery endarterectomy on outcomes during coronary artery bypass grafting. J Card Surg. 2011; 26: $247-53$.

25. Careaga RG, Salazar GD, Tellez LS, Arguero SR.
Coronary endarterectomy and bypass grafting without cardiopulmonary bypass. Rev Esp Cardiol. 2003; 56: 515-18.

26. Atik FA, Dallan LA, de Oliveira SA, Lisboa LA, Platania F, Cabral RH, Jatene AD. Myocardial revascularization with coronary endarterectomy. Stratification of risk factors for early mortality. Arq Bras Cardiol. 2000; 75: 269-80.

27. Ranjan R, Adhikary AB. Coronary endarterectomy in diffuse coronary artery disease. Dhaka. LAP Publishing, 2017. 